\title{
Influential Factors for Foreign Language Teaching
}

\author{
Yi-qun YIN \\ Foreign Languages Department, Dalian Institute of Science and Technology, China \\ yinyiqun666@163.com
}

Keywords: Foreign language teaching, Principles, Procedures, Materials, Testing

\begin{abstract}
To maximize the level of language learning, it is a big responsibility for teachers to choose best ways of teaching a foreign language. However, there is not such a method merely effective on teaching process and leading to success. So they should analyze the conditions, determine the techniques, and operate them in the classroom to get the best results as much as possible to the fullest. This paper will try to analyze some of key factors, which can affect foreign language teaching in terms of teaching principles, teaching procedures, materials and testing. Teachers can accomplish the ideal foreign language teaching goals as long as they apply these components appropriately.
\end{abstract}

\section{Introduction}

Language is a complicated component of the human nature. People may spend their whole life learning a foreign language and sometimes even their mother tongue in details. There are various reasons for people to learn a new language other than their mother tongue such as interest, migration, trade, love affairs, adventure, etc. However, each person has his/her own pace in the language learning process. It is not easy for learners to make great success when learning a foreign language. Although some people reach significant level, they still may not speak like native-speakers, and some even do not learn anything after trying many ways to learn the target language, and there are some in between. This is because of many variables that influence language learning process. Those can be the input of language itself structurally, the approaches and methods, techniques, strategies, psychological, physical and social factors, and etc. Therefore, there are a lot of things to be taken into account while teaching or learning a new language.

It is believed that there are two main contexts available as language learning environments. The first one is English as a Second Language (ESL), which is the setting that target language is used officially in state, educational institutions. The second one, which is the setting that the target language is neither the mother tongue of people nor the officially accepted language in that country, is English as a Foreign Language (EFL). When we refer to the subject in our country, we can say that China is an EFL country and language learning settings should be designed in respect of the criteria of EFL. There is a variety of approaches, methods and techniques to realize learning of a new language. However, there is not such a method merely effective on learning process and leading to succeed. Therefore, it is a big responsibility for the teachers to choose best ways of teaching a foreign language. They should analyze the conditions, determine the techniques, and utilize them in the classroom to get the best results as much as possible. The answers to influential factors for foreign language teaching can be diverse. This paper will try to analyze some of key factors in respect of the context of China by means of teaching principles, teaching procedures, materials and testing. 


\section{Important Factors Affecting Foreign Language Teaching}

\section{Teaching Principles}

Some of the early methods designed just to teach how to read the literature of the target language by using translation techniques or to communicate in the target language and think in Second Language by using only the target language with the help of demonstration and imitation and memorization in the classroom. On the other hand, some of the methods lay an emphasis on communication, social interaction, cooperative learning, etc. to foster language learning.

As all know, language is a tool for communication and interaction between human beings, it is how language is developed and used naturally. Therefore, it should be the case in language teaching. Learners can make progress when they learn the target language by communicating and interacting with each other. To allow them to communicate, teachers should provide the preconditions that combine foreign language teaching with the learning environment.

While providing the necessary elements, teachers should be the one that learners can trust the knowledge and accept. For the learners, it is so important that they see the teacher as a model for themselves, while the language level is increasing; learners start to understand that teachers also may not know everything. Learners and teachers can accept their weaknesses. Hence, mutual trust and tolerance is vital between learners and teachers who benefit from the process.

One of the factors can be the input that will cultivate the learners. However, any input may not guarantee the nurturing act. The input should be acceptable by the learners so that it can be both rewarding and challenging. That can make them to build up connections between their current knowledge and new knowledge that succeeds their present level slightly. However, comprehensible input may not be enough on its own. Using tasks, situations, and functions can be very helpful in language learning because they have the real-life experience and they are more naturalistic and meaningful than form-based settings. In a word, learners are immersing in the positive language environment, which is beneficial for them to learn the foreign language.

Lexicon can be referred as a kind of essential condition in language learning, and lexical development is important in understanding the messages and negotiating the meanings; that is, lexicon with a wider scope let learners become free and productive while they are working on language [1]. Besides, a big lexicon can make learners speak more fluently.

Language development can lead learners to think in Second Language. When they are sending or receiving messages if they have the image of what they want to say or of the idea that is sent to them in their minds, which refers to thinking in Second Language. Thinking in Second Language may help learners to be more successful in the target language learning. Hence, this will require productive output except comprehensible input. Learners should apply the language that they have already to communicate in the target language, negotiate the meanings. However, there is an important thing that must keep in mind. Sufficient production cannot occur easily. Learners should go through a nurturing and successful process while learning the language so that production can be achieved easily. Under the natural circumstance, language learning process as in first language acquisition, silent phases and errors can possibly take place [2]. Teachers should let them feel secure by tolerating those acts until learners come to a certain level. In error correction, however, teacher should decide immediate or delayed correction if it is necessary [3]. 
To make the learners feel without worrying about the process or making errors, teachers should build mutual trust between them and learners, and among learners. Learners may fear that they may make mistakes and be humiliated by their teachers or friends. Anxiety level may go up and learning may not take place in a unhindered sense or may not occur at all. Therefore, teachers should break down the psychological barriers in learners' minds. Moreover, teachers may let them to use mother tongue if learners and teachers feel it is the necessary to use it. Apart from mother tongue use, translation method can be utilized if necessary. These methods can make learners feel comfortable about their progress in language and can lower the affective filter of learners and allow them to learn in a relaxed way [3].

One of the best ways to help them in language learning process is to teach learning strate gies. Learning how to study can foster learners' development not only in language learning but any type of learning. Using strategies can be time-saving and fasten the learning speed.

Furthermore, learner-centered language teaching shows that peer-work and group-work can be very helpful to organize more communicative and interactive activities. The relationship among peers should certainly be based on trust, and so interaction between peers can produce good results. It is said that language is dialogic in nature, so peer or group activities make sense in promoting interaction between learners to some degree. As a result, teachers assign roles, so new identities for learners can make them more flexible about using the language or making mistakes, and reduce their anxiety level. Learners can use dialogs in tasks and situations, and functional statements in dialogs as a context to perform the new roles.

\section{Teaching Procedures}

When one considers the variety of levels, learners' aims, interests, needs, and etc. It may be impossible to outline specific in a way, standard procedural phases that can call upon all kinds of learners. However, after necessary adjustments are done, there are some activities that could be used among all learners based on the characteristics of learners.

A course may start with a lead-in activity. Teachers convey some information by associating it with the existing knowledge of learners. The information includes clues about the new topic. This can make learners build up connections between their past experiences and present topic. Lead-in section can contain brainstorming, problem and solution part, and a discussion part, which can make them prepare for the following role-playing task. Thus, learners may become curious about the subject and feel motivated about it.

After the lead-in section, the teacher comes up with the new topic, gives instructions about the activities and explains objectives of the lesson and possible outcomes. This movement can help learners to see the outline of the lesson and make them accept readily what will happen in the class. Instead, the unknown may cause stress. Teachers may assign the roles to learners to practice the dialogs that are in the task. This activity will give learners the opportunity to deal with authentic language because of the nature of task, which provides real-life experiences. Apart from the dialog, learners may need to utilize structures, if learners will feel comfortable and are willing to learn details, teacher should teach grammatical structures. This stage can lead them to master their interlanguage and manipulate it.

Hereafter, the learners may be given a video script that shows the dialog in real-life situation by natives, which can provide the opportunity to compare and contrast the authentic language and the language that learners produce. Teachers can set small group discussions about the task and dialogs allow learners to analyze the target language. Hence, the learners can understand the gaps between Second Language and their interlanguage. They can discuss the 
experience they have in the role-play and reflect their feelings, in which provides a kind of meaningful communication both in practice and discussion sections for learners.

Then, learners should have the opportunity to practice the language they work on in a similar or different task. That is, using the communicative expressions in the conversations under different contexts. It is helpful for them to master the language, manipulate it, and develop their own lexicon with the support of a variety of materials such as pictures, internet, games, and etc. Spoken activities should be transferred from guided to free practices. Thus, primarily, learners can understand the rules of target language and then grasp it, and make it their own language.

In the following stage, teachers should let the learners reflect on their own learning process and make comments on the teaching act, subject, and materials. Feedback of peers activity should be supported and teachers should tell them that learners' comments and feedback are worth to share. Teachers themselves should share the views with learners, and the interaction should be more constructive rather than corrective. Thus, learners will meet the satisfaction of having a more knowledgeable person in the class when they struggle for learning.

In the last stage, teachers may give homework that require cooperation of a group of learners, which is the core of cooperative language learning, analyzing the homework, sharing ideas and discussing, and preparing a final product. It requires them to speak in the target language throughout the process but not in a forcible way. Teachers should make the learners believe that teachers trust them about their study. However, in each level or with every learner, cooperation may not be easily realized because of various reasons. Then, teachers can give homework that requires creative production that learners can use the strategies and skills, learners can benefit from their dominant intelligences and the other abilities as much as possible. It may promote personal language development of learners.

\section{Teaching Materials}

Materials are the supportive elements of language education as one of the sources of input, practice, common sense, etc. Teachers and learners can benefit a lot from carefully selected materials. To make this selection more precise, teacher should do needs-analysis with the learners to collect data about their levels, needs, interests, motivations, learning strategies, dominant intelligences, and anything that can affect the learning/teaching process.

When we stress the input factor, materials can be categorized into two categories: authentic materials and created materials. Authentic ones that provide the carrier of the actual use of target language by native speakers in real situation, and created ones are altered and simplified in terms of the receiver of the input. Authentic materials can be the real language practice tools under native language instruction. Created materials can be seen as sources and textbooks that are purposefully produced for language teaching. Authentic materials are generally selected by language teaching methodologists, teachers, and learners because they provide real and meaningful communication opportunities. However, created materials may only be preferred in certain circumstances when authentic material is useless and meaningless or if there is a need to teach a specific knowledge to learners by teacher. Moreover, one thing that we have to mention here; whatever the material type is (authentic or created), the input should be accepted readily for learners. If the complexity is superior to the levels of learners, learners may not understand and handle the language, lose their motivation, concentration and at the end there may be no product at all. If it is inferior to the levels of learners, learners may not find it challenging, worth studying and even they may feel as if they are treated like children. It can be annoying for them. 
For lower level learners, teachers would rather use any materials than the source of content, practice and feedback. In addition, the text books, which are available for beginners, may not be suitable for their levels all the time. Then, teachers may prefer to use story books, poems, songs, comics, games, etc. as the sources of input, content and activity for the lesson. These materials can be more interesting, attractive, motivating and fit for lower level learners, especially for young learners, who may easily get bored and have low concentration, and even sometimes for adults. In addition to these materials, arts and crafts projects can be incorporated into the teaching act.

When the level is going upward, teacher should pay attention to diversity in materials as audio, visual, and audio-visual materials, such as videos, cassettes, pictures, maps, CDs, DVDs, charts and etc. These methods can call on different sensory systems of learners because each learner has his/her individual characters, differences, and strategies to use. Teachers' responsibility is to offer various materials as much as possible. Furthermore, realia, which are not only made for language teaching purpose, such as newspaper, TV, radio, internet can be effectively utilized in classes after careful selection of content. Games can also be very useful methods, because language is not the aim but the tool to reach the goal, so learners will want to use the language properly to win the game. For all levels of learners, role-playing is a good chance to practice and check their language skills at the stage when they interactively communicate with the other characters in a real situation. In a play, the learner feels at ease to use language with a new identity that is different from his/her real identity, which can reduce the anxiety level and raise the productivity easily.

\section{Testing}

In general, testing is finding out how well something works. It is not only the content the teacher teach but anything that is used to develop language skills. In testing, the criteria should be based on communicative use of target language and the strategies that provide successful language learning to the learners [3]. However, it is essential that teachers should avoid decontextualization of test items. This may cause problems for both the learners and the teachers. The learners may not easily build connections between the questions and what they have learnt in the lesson. All the teaching process is bound to test learners' memorization ability. Besides, it can be such a demanding task for teachers to prepare these kinds of tests. To avoid this, teachers should look for real-life contexts that are familiar to learners and then they can adapt to them, if necessary, including linguistic and lexical items that are required to construct answers.

Teachers want to know learners' communicative and meaningful language competence and pragmatic use of language, test items should be presented in a context. Then, the teacher may apply communicative evaluation tools that require creative productions. Those can be comprehensive tests with open-ended questions, like presentations, interviews, essays, etc. This type of evaluation can show whether the process is helpful to make the learners study the target language and use it accurately and fluently.

Assessment should be qualitative rather than quantitative that learners can easily understand what is going wrong with their language learning process or what is going smoothly. Teachers should be instructive while giving feedback to learners. Not only can this movement encourage them but also make them feel that they are respected by their teachers. 


\section{Conclusions}

The paper tries to describe the key factors that may be suitable to create an ideal foreign language teaching setting. The teaching principles, procedures, materials and testing that are explained briefly. In addition to the above principles, there may be many more techniques and principles and ways to build successful language learning environment, however, those techniques and principles should be selected and constructed on a basis of the context they are used.

\section{References}

[1] J. C. Richards \& T. S. Rodgers. Approaches and Methods in Language Teaching, Cambridge University Press, United States of America, 2002.

[2] R. Ellis. The Study of Second Language Acquisition, Second Ed., Oxford University Press, China, 2008.

[3] D. Larsen-Freeman. Techniques and Principles in Language Teaching, Oxford University Press, China, 2003. 